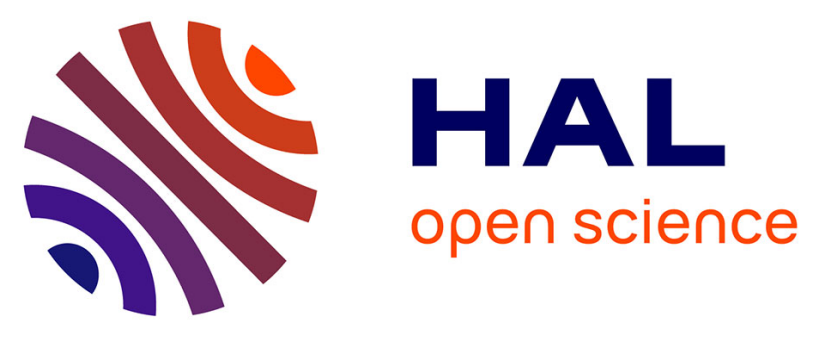

\title{
Phenylazide Hybrid-Silica - Polarization Platform for Dynamic Nuclear Polarization at Cryogenic Temperatures
}

Wolfram R Grüning, Harald Bieringer, Martin Schwarzwalder, David Gajan, Aurélien Bornet, Basile Vuichoud, Jonas Milani, David Baudouin, Laurent Veyre, Anne Lesage, et al.

\section{To cite this version:}

Wolfram R Grüning, Harald Bieringer, Martin Schwarzwalder, David Gajan, Aurélien Bornet, et al.. Phenylazide Hybrid-Silica - Polarization Platform for Dynamic Nuclear Polarization at Cryogenic Temperatures. Helvetica Chimica Acta, 2017, 100 (1), pp.e1600122. 10.1002/hlca.201600122 . hal01838493

\section{HAL Id: hal-01838493 https://hal.science/hal-01838493}

Submitted on 13 Jul 2018

HAL is a multi-disciplinary open access archive for the deposit and dissemination of scientific research documents, whether they are published or not. The documents may come from teaching and research institutions in France or abroad, or from public or private research centers.
L'archive ouverte pluridisciplinaire HAL, est destinée au dépôt et à la diffusion de documents scientifiques de niveau recherche, publiés ou non, émanant des établissements d'enseignement et de recherche français ou étrangers, des laboratoires publics ou privés. 


\title{
Phenylazide Hybrid-Silica - Polarization Platform for Dynamic Nuclear Polarization at Cryogenic Temperatures
}

\author{
Wolfram R. Grüning, Harald Bieringer, Martin Schwarzwälder, David Gajan, Aurélien Bornet, Basile Vuichoud, \\ Jonas Milani, David Baudouin, Laurent Veyre, Anne Lesage, Sami Jannin, Geoffrey Bodenhausen, Chloé \\ Thieuleux, ${ }^{*}$ Christophe Copéret*
}

\begin{abstract}
Hyperpolarization of NMR-active nuclei is key to gather high quality spectra of rare species and insensitive isotopes. We have recently established that silica-based materials containing regularly distributed nitroxyl radicals connected to the silica matrix by flexible linkers can serve as promising polarization matrices in DNP. Here we investigate the influence of the linker on the efficiency of the polarization. The materials were fully characterized and exhibit high surface areas and narrow pore size distributions with a tunable amount of phenyl azide groups over a broad range of concentrations. The phenyl azide groups can be easily functionalized via a two-step procedure into 4-carboxy-2,2,6,6tetramethyl-1-oxyl-piperidine (TEMPO) to give polarizing matrices with controllable radical content. The DNP efficiency was found to be similar as in materials with flexible linkers, both for MAS at 105 $\mathrm{K}$ and dissolution DNP at $4 \mathrm{~K}$.
\end{abstract}

[a] Dr. W. R. Grüning, H. Bieringer, Dr. M. Schwarzwälder, Prof. C. Copéret

Department of Chemistry and Applied Biosciences ETH Zürich

Vladimir-Prelog-Weg 1-5/10, 8093 Zürich, Switzerland

E-mail: ccoperet@ethz.ch

[b] Dr. D. Gajan, Dr. A. Lesage

Centre de Résonance Magnétique Nucléaire (RMN) à Très Hauts Champs, Institut des Sciences Analytiques [Centre National de la Recherche Scientifique (CNRS)/Ecole Normale Supérieure (ENS) Lyon/Université Claude Bernard Lyon 1 (UCBL)] Université de Lyon, 69100 Villeurbanne, France

[c] Dr. A. Bornet, Dr. B. Vuichoud, Dr. J. Milani, Prof. L. Emsley, Dr. S. Jannin, Prof. G. Bodenhausen

Institut des Sciences et Ingénierie Chimiques

Ecole Polytechnique Fédérale de Lausanne (EPFL) 1015 Lausanne, Switzerland

[d] Dr. D. Baudouin, Mr. L. Veyre, Dr. C. Thieuleux Institut de Chimie de Lyon, Laboratoire de Chimie, Catalyse, Polymères et Procédés (LC2P2), Unité Mixte de Recherche (UMR) 5265 CNRS- CPE Lyon- UCBL, CPE Lyon

Université de Lyon, 69100 Villeurbanne, France E-Mail : Chloe.THIEULEUX@univ-lyon1.fr

[e] Département de Chimie, Ecole Normale Supérieure (ENS)-Paris Sciences et Lettres (PSL) Research University; Laboratoire de Biomolécules (LBM), Université Pierre et Marie Curie (UPMC) Université Paris 06, Sorbonnes Universités; Laboratoire de Biomolécules (LBM), Unité Mixte de Recherche (UMR) 7203 Centre National de la Recherche Scientifique (CNRS), F-75005 Paris, France

\section{Introduction}

Generating hyperpolarized samples for magnetic resonance imaging (MRI) and nuclear magnetic resonance (NMR) spectroscopy is of great interest because it enables sensitivity enhancements by several orders of magnitude. ${ }^{[1]}$ In this context, Dynamic Nuclear Polarization (DNP) at cryogenic temperatures has been a very active field of research in the past few years, leading to tremendous progress in radical design and instrumentation, and opening new applications in solids under Magic Angle Spinning (MAS) as well as in solution after rapid dissolution. ${ }^{[1 \mathrm{c}, 2]}$ DNP-enhanced MAS NMR and dissolution DNP both rely on the transfer of electron spin polarization to the surrounding NMR-active nuclei ${ }^{[3]}$ by saturating the EPR (Electron Paramagnetic Resonance) transitions at low temperatures $(1.2-105 \mathrm{~K})$. For that purpose a polarizing agent (PA), e.g., a persistent organic radical, and an analyte are comixed in solution and shock-frozen, usually into a glassy matrix. The transfer of polarization from electrons to protons in solids relies on three mechanisms: the solid effect (one electron and one nucleus), the cross effect (two electrons and one nucleus) and thermal mixing (involving many electrons) ${ }^{[4]}$. Overhauser effects have been recently reported as a fourth mechanisms in insulating solids. ${ }^{[5]}$ The cross effect and thermal mixing, which are the most relevant for DNP MAS NMR and dissolution DNP, respectively, require appropriate dipolar couplings between electrons to be efficient. ${ }^{[6]}$ In glassy frozen solutions of monoradicals, the dipolar coupling strengths span a wide range because of the random spatial distribution of the free electrons. For mono-radicals, the concentration of the PA (usually around $10^{19}$ spins/mL or $25 \mathrm{mM}$ ) is the only parameter that allows one to adjust the inter-radical distances, and hence the electronelectron dipolar couplings, which are in fine critical for the DNP efficiency in frozen glasses. To acquire a better control, we have recently introduced solid polarizing matrices made of mesostructured hybrid silica featuring TEMPO radicals distributed homogeneously on the surface of the pores and demonstrated that they could be successfully used for DNP both near 4 and $105 \mathrm{~K} \cdot{ }^{[7]}$. Here we use the term homogeneous in the sense of a narrow statistical distribution as it would be found in a solution of non-interacting molecules. We do not intend to imply an ordered mono-spaced arrangement of molecules. In the first generation of these materials (named HYPSO-1), the TEMPO moieties were attached to the silica surface via a propyl chain. Tailoring the distribution of radicals along the silica pore channels turned out to be key for maximizing the proton polarization and hence achieving high enhancements. The nature of the linker anchoring the TEMPO radicals to the surface of the hybrid material, flexible vs. rigid, is expected to be important parameter. In a different context, namely in catalysis, ${ }^{[8]}$ we have recently reported that flexible 
tethers in functionalized hybrid materials enable interactions of the organic moieties with the silica surface, thus improving the catalytic performance by stabilizing reaction intermediates.

Here we describe the synthesis and characterization of a solid-state polarization matrix in which the TEMPO moiety is covalently linked to the silica surface via a rigid tether consisting of a phenyl ring (coined HYPSO-4), The performance of this material is investigated under both solidstate MAS and dissolution DNP conditions, and compared to those of HYPSO-1 where the radicals were anchored at the surface via flexible alkyl chains. ${ }^{[7]}$

\section{Results and Discussion}

The materials were prepared using apolar phenylazido silicon molecular precursors which can be readily introduced into hybrid silicas over a broad range of concentrations without compromising the structuration of the materials. The TEMPO moiety can then easily be introduced through a peptide coupling step after reduction of the azido into an amino functionality (Scheme 1B). The synthesis of the azide-precursor 1 is shown in Scheme 2; it was readily prepared in two steps by monosilylation of 1,4-diiodobenzene 2 yielding 4-iodophenyltri(isopropoxy)silane $3^{[9]}$ followed by a copper-catalyzed iodideazide exchange. ${ }^{[10]}$ In a second step, materials with different concentrations of organic functionalities were synthesized by a sol-gel process under acidic conditions (pre-hydrolysis step) in the presence of $\mathrm{EO}_{20} \mathrm{PO}_{70} \mathrm{EO}_{20}$ (Pluronic ${ }^{\circledR} \mathrm{P} 123$ ) as structuredirecting agent (SDA) followed by the addition of sodium fluoride (condensation step) as depicted in Scheme 2. ${ }^{[11]}$

Materials were synthesized in four decreasing concentrations from 1 with 1:Si(OEt $)_{4}$ ratios of 1:34, 1:55, 1:100, and 1:200. The SDA was subsequently removed by extraction with pyridinium hydrochloride and the materials were dried under high vacuum. ${ }^{[12]}$ The MatPhN $_{3}$ materials exhibit type IV isotherms in $\mathrm{N}_{2}$ ad-/desorption at $77 \mathrm{~K}$ typical of highly mesoporous solids. Brunauer Emmett Teller ${ }^{[13]}$ (BET) surface areas are consistently high $\left(>700 \mathrm{~m}^{2} \mathrm{~g}^{-1}\right)$. Pore sizes between 8-10 nm are calculated using the Barnett Joyner Halenda method at the adsorption branch of the isotherms ${ }^{[14]}$. The pore size increases with decreasing concentrations of organic precursors. TEM of the materials reveals a worm-like porous network for the most concentrated material. The network evolves towards a 2D hexagonal arrangement with decreasing concentrations, as confirmed by small angle $\mathrm{X}$-ray scattering which shows a single intense broad signal at $2 \Theta \approx 0.75^{\circ}$ (ca. 12 $\mathrm{nm})$.
A)

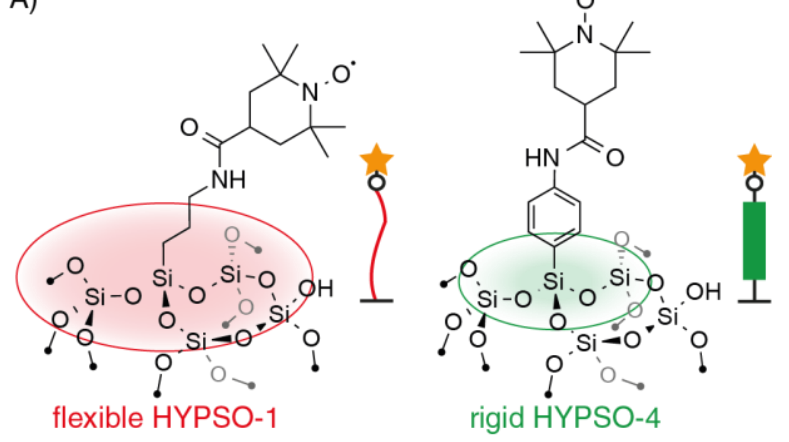

B)
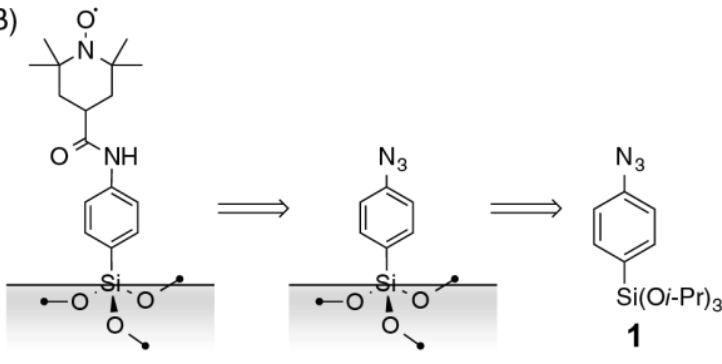

Scheme 1. A) HYPSO-1 with flexible linker vs. HYPSO-4 with a rigid linker. B) Retrosynthesis of HYPSO-4.

Manipulation of the nitrogen-containing functionality leads to the final material in two steps: ${ }^{[7 a, 11 d]}$ i) the azide materials MatPhN $\mathbf{N}_{3}$ are first reacted with dimethylphenylphosphine in a Staudinger reduction ${ }^{[15]}$ to yield the corresponding aniline materials $\mathrm{MatPhNH}_{2}$ and ii) the TEMPO moiety is introduced through a classical amide coupling using 4-TEMPO carboxylic acid anhydride (5), yielding MatPhTEMPO, hereafter referred to as HYPSO-4.0. The surface area remained high throughout all subsequent post-synthetic modifications.

DRIFT spectra of the materials were acquired at each synthetic stage. All spectra show the characteristic stretching bands corresponding to isolated and bridged silanols at 3740 and $3550 \mathrm{~cm}^{-1}$ respectively. The DRIFT spectrum of the azide material $\mathrm{MatPhN}_{3}$ (SI) shows two strong bands at 2133 and $2104 \mathrm{~cm}^{-1}$ characteristic of azide groups. These are only slightly shifted compared to 2126 and $2094 \mathrm{~cm}^{-1}$ of the molecular precursor 1. The appearance of two bands has been attributed to a Fermi resonance in the phenyl azide materials. ${ }^{[16]}$ The azide groups were quantitatively converted to the corresponding amines, as evidenced by IR, in contrast to materials containing propyl linkers, for which a substantial fraction (ca. 20\%) of residual azide groups were observed suggesting that the phenyl azide groups, in contrast to the propyl azide groups, are exclusively located in the mesopores rather than in the less accessible micropores of the materials. The spectra also contain $\mathrm{C}-\mathrm{H}$ bands at 2955 and $2853 \mathrm{~cm}^{-1}$ characteristic for surface methoxy groups. The aniline $\mathrm{N}-\mathrm{H}_{s t}$ band overlaps with the bridging silanols, as the band would be expected at $3368 \mathrm{~cm}^{-1}$ like in the molecular analogue 4 (4triethoxysilylaniline). 


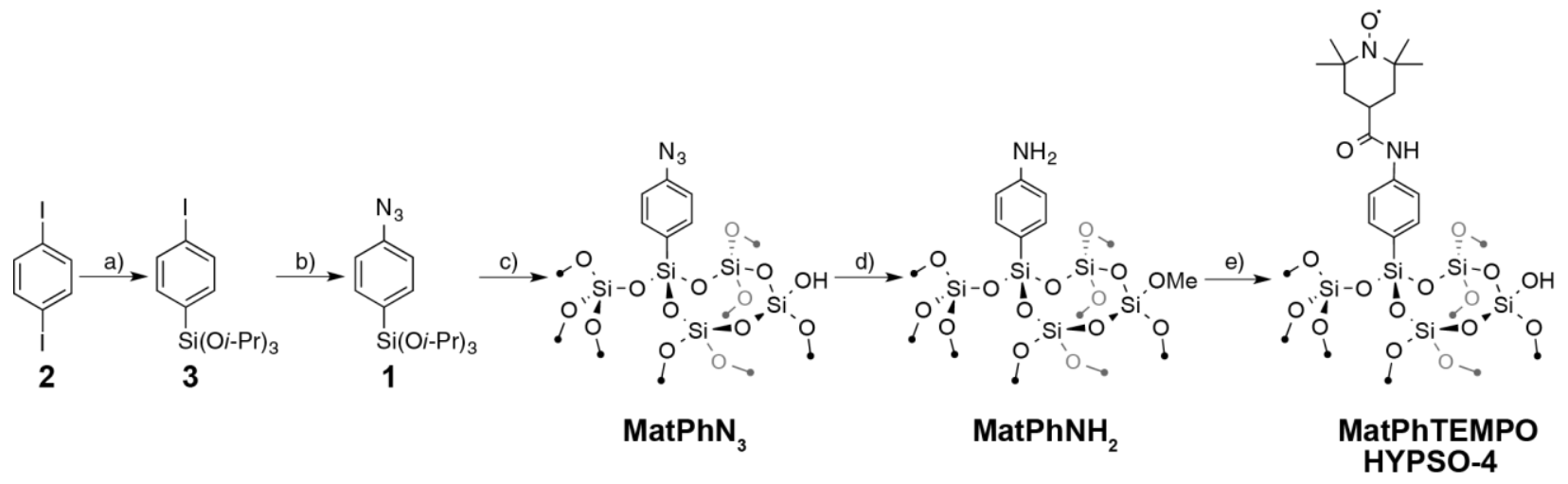

Scheme 2. Synthesis of 4 -tri-i-propoxysilylphenylazide, materials and post-synthetic functionalization 1. a) 1$) n-\mathrm{BuLi}, \mathrm{Et} 2 \mathrm{O}-78^{\circ} \mathrm{C}$ to $\left.0^{\circ} \mathrm{C}, 1 \mathrm{~h} ; 2\right) \mathrm{CISi}(\mathrm{O} \text { - } \mathrm{Pr})_{3}$, $\mathrm{Et}_{2} \mathrm{O},-78^{\circ} \mathrm{C}$ to $25^{\circ} \mathrm{C} 12$ h. b) $\mathrm{NaN}_{3}$, Cul $\left(5-10 \mathrm{~mol} \%\right.$ ), Na-L-prolinate, DMSO, $65^{\circ} \mathrm{C}, 7 \mathrm{~h} .22 \%$ over 2 steps c) 1) Si(OEt) ${ }_{4}$ (n equiv.) $\mathrm{NaF}, \mathrm{P} 123$, aq. $\mathrm{HCl}$ pH 1.5 , $40^{\circ} \mathrm{C}, 72 \mathrm{~h}$. 2) py, aq. $\mathrm{HCl}, 70^{\circ} \mathrm{C}, 16$ h. d) 1) $\mathrm{PMe}_{2} \mathrm{Ph}, \mathrm{THF}, 0^{\circ} \mathrm{C}$ to $25^{\circ} \mathrm{C}, 22$ h. 2) $\mathrm{H}_{2} \mathrm{O} / \mathrm{MeOH}$. 3) MeOH Soxhlet extraction, 48 h. e) $4-\mathrm{TEMPO}-\mathrm{Anhydride} 5$, DMAP, $\mathrm{CH}_{2} \mathrm{Cl}_{2}, 25^{\circ} \mathrm{C}, 48 \mathrm{~h}$.

After introducing the TEMPO moiety, the bands associated with surface methoxy groups disappear from the spectrum of HYPSO-4 (SI). Furthermore, the introduction of the amide functionality is confirmed by the appearance of the two bands at ca. 1680 and $1502 \mathrm{~cm}^{-1}$.

Further characterization was obtained by conventional roomtemperature solid-state NMR spectroscopy and DNP Surface Enhanced NMR Spectroscopy (DNP-SENS) near $105 \mathrm{~K}^{[17]}$ The carbon-13 CP-MAS (Cross-Polarization Magic-Angle Spinning) spectrum of MatPhN $_{3}$ (Figure 1A) shows four peaks at 143, 135, 126 and $118 \mathrm{ppm}$ assigned to the carbons of the phenyl ring, since these chemical shifts are almost identical to those of precursor 1. While larger line widths are observed for the DNP. SENS spectrum, due to the presence of exogenous radicals and to the low temperature of the sample, recording a $2 \mathrm{D}{ }^{1} \mathrm{H}^{13} \mathrm{C}$ HETCOR spectrum (SI) allowed corroborating the assignment. In addition, the ${ }^{29} \mathrm{Si}$ spectrum (SI) shows a signal at $-80 \mathrm{ppm}$ associated with $T$-substructures $\left(\mathrm{T}^{3}\right)$ along with more intense signals at $-110 \mathrm{ppm}$ corresponding to $Q$-substructures of bulk silica. Along similar lines, the ${ }^{13} \mathrm{C}$-spectrum of $\mathbf{M a t P h N H}_{2}$ (Figure 1B) reveals the characteristic shift of the resonance at $148 \mathrm{ppm}$ of the quaternary carbon in position 1 of the phenyl ring, while the remaining resonances of the phenyl ring are observed at 137 and $114 \mathrm{ppm}$, in very good agreement with the analogous compound 4. Note the presence of an intense resonance of the surface methoxy groups at $55 \mathrm{ppm}$. The ${ }^{1} \mathrm{H}-{ }^{13} \mathrm{C}$ HETCOR DNPSENS spectrum (SI) also corroborates the assignment, while the ${ }^{29}$ Si DNP-SENS spectrum (SI) remains unchanged.
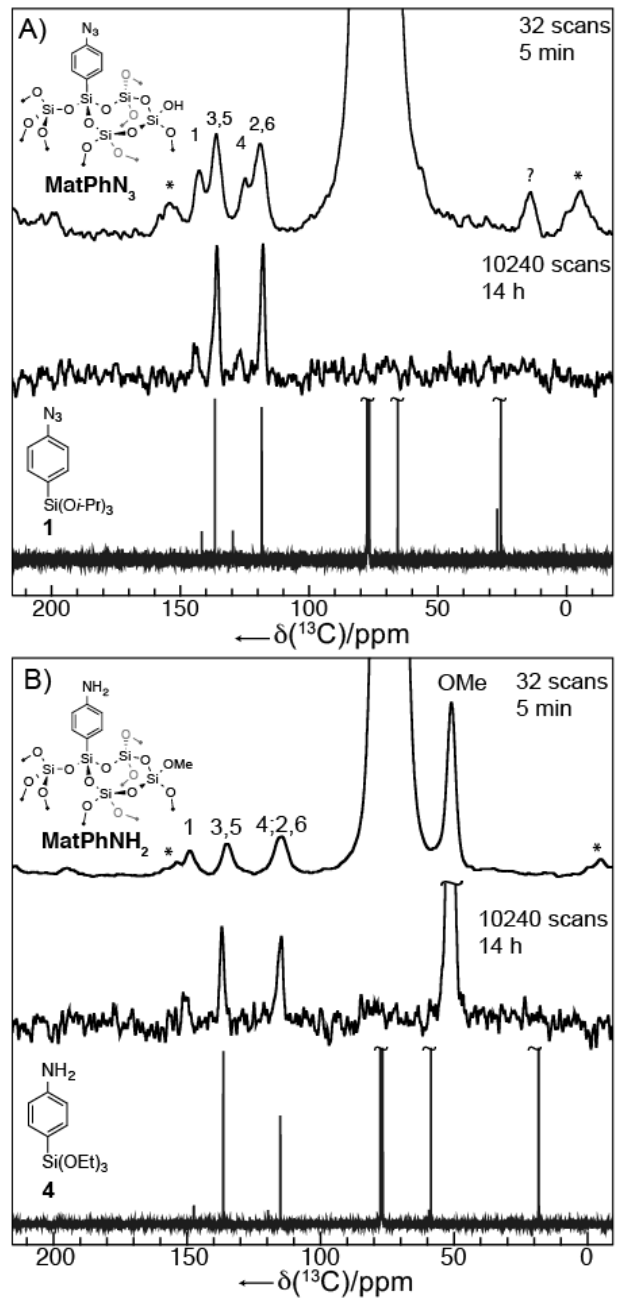

Figure $1 \mathrm{~A}){ }^{13} \mathrm{C}$ NMR spectra at $100 \mathrm{MHz}$ of $\mathrm{MatPhN}_{3}$ : DNP-SENS CPMAS spectrum at $105 \mathrm{~K}$ (,top), room temperature CP-MAS spectrum (176 $\mathrm{MHz}$ middle) and ${ }^{13} \mathrm{C}$ solution-state NMR spectrum of the precursor 1 (in $\mathrm{CDCl}_{3}, 75 \mathrm{MHz}$; bottom) B) ${ }^{13} \mathrm{C}$-NMR spectra of MatPhNH $\mathrm{M}_{2}$ : DNP-SENS CPMAS spectrum $100 \mathrm{MHz}$ (,top), room temperature CP-MAS spectrum (176 $\mathrm{MHz}$, middle) and ${ }^{13} \mathrm{C}$ solution-state NMR spectrum of the precursor 4 (in $\mathrm{CDCl}_{3}, 75 \mathrm{MHz}$; bottom). The DNP-SENS and CPMAS spectra were acquired with 32 and 10240 scans respectively and processed with an exponential line broadening of $100 \mathrm{~Hz}$. 
Finally, HYPSO-4 materials were further analyzed by EPR spectroscopy in order to evaluate the radical content by spin count experiments and the radical distribution through line width analysis (Figure 2). ${ }^{[7]}$ The radical content was found to be in the range of $0.16-0.016 \mathrm{mmol} \mathrm{g}^{-1}$ (Figure 2A), which corresponds to an overall synthetic efficiency of $24-37 \%$, slightly better than for HYPSO-1 (17-32\%). Figure 2B shows a slight linear broadening of the EPR line width of HYPSO-4 with increasing radical concentration from 11.7 to $13.9 \mathrm{G}$. This broadening is less pronounced than for HYPSO-1 for which a line width of $15.3 \mathrm{G}$ was found for a comparable radical concentration $\left(0.14 \mathrm{mmol} \cdot \mathrm{g}^{-1}\right)$. These reduced line widths at high radical concentrations $\left(>0.135 \mathrm{mmol} \mathrm{g}^{-1}\right.$ ) reflect a larger mean radicalradical distance for HYPSO-4 than for HYPSO-1, and hence a better radical distribution. This can be attributed, for a given PA concentration, either to a greater surface area or to a more uniform distribution of radicals on the surface.
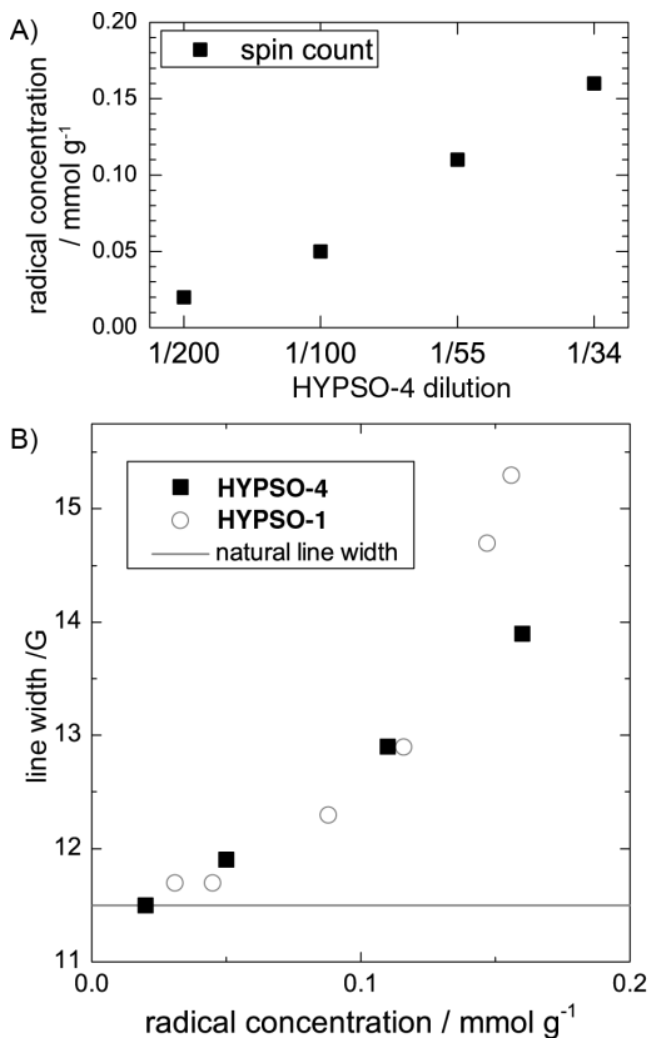

Figure 2 A) radical concentration vs. precursor dilution ratio. B) X-band EPR line width vs. radical concentration.

With these promising EPR data in hand, the materials were impregnated with $\mathrm{C}_{2} \mathrm{H}_{2} \mathrm{Cl}_{4}$ and their DNP performance was evaluated under MAS conditions at ca. $105 \mathrm{~K}$ and $9.4 \mathrm{~T}$ (Figure $3)$. The enhancements of the solvent proton, carbon and surface silicon resonances increase from $\varepsilon\left({ }^{1} \mathrm{H}\right) / \varepsilon\left({ }^{13} \mathrm{C}\right) / \varepsilon\left({ }^{29} \mathrm{Si}\right)=3.6 / 4.2 /$ 3.1 for HYPSO-4 $1 / 200\left(0.02 \mathrm{mmol}\right.$ (radical) $\left.\cdot \mathrm{g}^{-1}\right)$ to $12.1 / 13.3 /$ 9.2 for the $1 / 55$ material $\left(0.11 \mathrm{mmol}\right.$ (radical) $\left.\cdot \mathrm{g}^{-1}\right)$. Further increasing the radical concentration does not increase the enhancement, which reaches a plateau at ca. $(10.9,13.5,9.5)$ for HYPSO-4 $1 / 34\left(0.16 \mathrm{mmol}\right.$ (radical) $\left.\cdot \mathrm{g}^{-1}\right)$. This plateau is similar to that obtained for HYPSO-1 $1 / 34(0.10 \mathrm{mmol}$ (radical) $\cdot \mathrm{g}$ $\left.{ }^{1}\right)$ : $(13.2,13.3,13.3)$ under identical experimental conditions on the same instrument. ${ }^{[7 a]}$ The presence of a plateau at high radical concentrations in HYPSO-4 stands in contrast to the decrease observed for HYPSO-1 (see ref. 14) and suggests that HYPSO-4 reduces large and unfavorable electron-electron dipolar interactions at high radical coverage.

When the material is wetted with either pure water or an aqueous $0.1 \mathrm{M}$ solution of $\left[{ }^{13} \mathrm{C}\right]_{5}$-proline, a very similar enhancement curve is obtained, with $\varepsilon\left({ }^{13} \mathrm{C}\right)=2.1$ for the very diluted HYPSO-4 1/200, increasing to a maximum $\varepsilon\left({ }^{13} \mathrm{C}\right)=22$ for HYPSO-4 1/55, the latter being somewhat below $\varepsilon\left({ }^{13} \mathrm{C}\right)=32$ found for HYPSO-1 1/34. ${ }^{7 a}$

We also investigated the performance for dissolution-DNP experiments. The ${ }^{1} \mathrm{H}$ polarizations $P\left({ }^{1} \mathrm{H}\right)$ and the corresponding build-up times were measured at $4.2 \mathrm{~K}$ and $6.7 \mathrm{~T}^{\left[{ }^{[18]}\right.}$ for the same set of materials wetted with $\mathrm{H}_{2} \mathrm{O}: \mathrm{D}_{2} \mathrm{O}$ (1:9) (Fig. 4.) The polarization $P\left({ }^{1} \mathrm{H}\right)$ after $300 \mathrm{~s}$ and build-up times $\tau_{\mathrm{DNP}}$ are compared in Table 1. The polarization increases from $2.3 \%$ for of HYPSO-4 1/34 to $9.6 \%$ for HYPSO-4 $1 / 55$ before decreasing to $7.8 \%$ and $2.8 \%$ for HYPSO-4 $1 / 100$ and $1 / 200$. Note that after $600 \mathrm{~s}$ the polarization reached $P\left({ }^{1} \mathrm{H}\right)=11.0 \%$ for HYPSO-4 $1 / 100$ whereas it remained nearly constant for the HYPSO-4 $1 / 55$ and reaches $10.2 \%$ for the most diluted sample, in line with its slower build up.

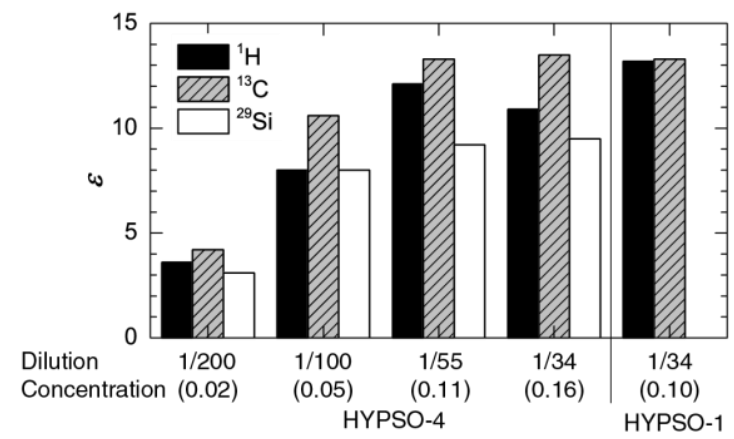

Figure 3 DNP enhancements for materials with different radical concentrations $\left(\mathrm{mmol} \cdot \mathrm{g}^{-1}\right)$ of HYPSO-4 wetted with $\mathrm{C}_{2} \mathrm{H}_{2} \mathrm{Cl}_{4}$. The spectra were acquired at ca. $105 \mathrm{~K}$ on a Bruker 9.4 T DNP solid-state NMR spectrometer equipped with an Avance III console and a low-temperature $3.2 \mathrm{~mm}$ triple resonance probe. The sample spinning frequency was $12 \mathrm{kHz}$ for ${ }^{1} \mathrm{H}$ and ${ }^{13} \mathrm{C}$, and $8 \mathrm{kHz}$ for ${ }^{29} \mathrm{Si}$.

Two regimes of polarization kinetics are observed: the more concentrated HYPSO-4 $1 / 34$ and $1 / 55$ show a rapid, almost perfectly mono-exponential build-up of the polarization whereas the more diluted HYPSO-4 1/100 and 1/200 show a slower biexponential build-up. We attribute the fast component to the direct polarization of protons by the radicals and the slow component to the propagation of the polarization by nuclear spin diffusion to sample areas where DNP is less effective.

The material HYPSO-4 1/55, which shows the most favorable polarization kinetics, was investigated at $1.2 \mathrm{~K}$. The ${ }^{1} \mathrm{H}$ polarization build-up (SI) can be characterized by two build-up times $\tau_{\mathrm{DNP}}{ }^{\text {fast }}=20 \mathrm{~s}$ and $\tau_{\mathrm{DNP}}{ }^{\text {slow }}=104 \mathrm{~s}$. 


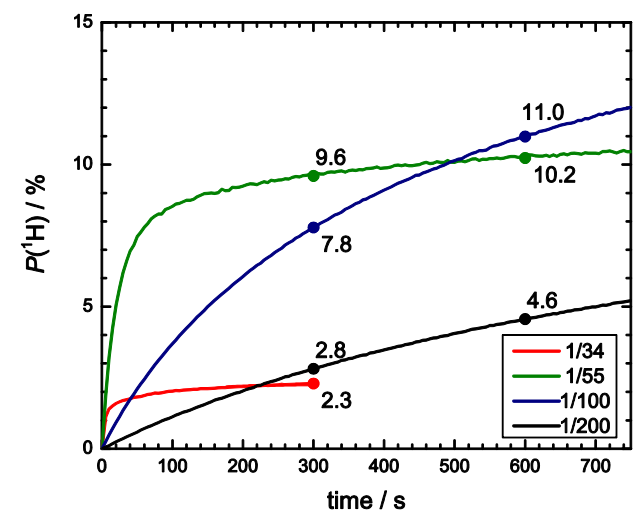

Figure 4. Polarization build-up at $4.2 \mathrm{~K}$ and $6.7 \mathrm{~T}$ for HYPSO-4 with different radical concentrations expressed in terms of dilution ratios.

\section{Conclusions}

We have characterized high surface area hybrid silica materials with a worm-like arrangement of the porous network containing rigid 1,4-phenylene tethers. The phenylazide groups are uniformly incorporated and readily amenable to functionalization, allowing the homogeneous introduction of radicals with a broad range of concentrations, as demonstrated by narrow EPR linewidths even for the most concentrated materials. HYPSO-4 shows enhancements in MAS-DNP over a broader range of concentrations than the HYPSO 1 and 2 having flexible linkers. The polarization build-up at 1.2 and $4 \mathrm{~K}$ is suitable for Dissolution-DNP. This study suggests that the unfavorable electron-electron dipolar interactions are reduced with HYPSO-4 at high PA concentration $(0,16 \mathrm{mmol} / \mathrm{g})$, which translates into high enhancements when $\mathrm{C}_{2} \mathrm{H}_{2} \mathrm{Cl}_{4}$ is used to wet the solid. However, this result does not translate directly into a higher proton polarization for dissolution DNP. We are currently exploring complementary molecular design to improve the polarization and understand the role of different features of the materials.

\section{Experimental Section}

General procedure. All used chemicals are commercially available und were used without further purification, except $\mathrm{CISi}(\mathrm{O} i-\mathrm{Pr})_{3}$ that was prepared from $\mathrm{SiCl}_{4}$ and iso-propanol and purified by distillation. Dry solvents and glassware as well as argon or nitrogen as inert gases were used whenever appropriate. A blast shield was used for reactions involving molecular azides.

Synthesis of 4-(Triisopropoxysilyl)-iodobenzene (3). p-diiodobenzene $2(7.50 \mathrm{~g}, 22.7 \mathrm{mmol})$ was put into a $250 \mathrm{~mL}$ Schlenk-flask and dissolved in $\mathrm{Et}_{2} \mathrm{O}(100 \mathrm{~mL})$. The solution was cooled to $-78^{\circ} \mathrm{C}$ (acetone $\left./ \mathrm{CO}_{2}(\mathrm{~s})\right)$ and $n$-BuLi (14.2 mL, $22.7 \mathrm{mmol}, 1.6 \mathrm{M}$ in hexane) was added dropwise with a syringe. After complete addition, the mixture was warmed to $0^{\circ} \mathrm{C}$ and stirred for $1 \mathrm{~h}$. Then, the solution was cooled to $-78^{\circ} \mathrm{C}$ and was slowly transferred via a cannula into a $250 \mathrm{~mL}$ two-necked flask, containing a vigorously stirred solution of $\mathrm{ClSi}(\mathrm{O} i-\mathrm{Pr})_{3}(17.5 \mathrm{~mL}, 68.2 \mathrm{mmol})$ in $\mathrm{Et}_{2} \mathrm{O}$ $(30 \mathrm{~mL})$ at $-78^{\circ} \mathrm{C}$. After complete addition, the resulting green solution was warmed to $25^{\circ} \mathrm{C}$ and stirred for $18 \mathrm{~h}$. The solution was then filtrated (celite and activated charcoal) and the solvent was removed under reduced pressure. The product was purified by Kugelrohr distillation. 4(Triisopropoxysilyl)-iodobenzene (3) was obtained as colorless liquid (6.44 g, $69 \%) .{ }^{1} \mathrm{H}$ NMR $\left(300 \mathrm{MHz}, \mathrm{CDCl}_{3}\right) \delta / \mathrm{ppm}=7.71(\mathrm{~m}, 2 \mathrm{H}), 7.39(\mathrm{~m}$, $2 \mathrm{H}), 4.24$ (septet, $\mathrm{J}=6.1 \mathrm{~Hz}, 3 \mathrm{H}), 1.20(\mathrm{~d}, \mathrm{~J}=6.1 \mathrm{~Hz}, 18 \mathrm{H}) .{ }^{13} \mathrm{C}$ NMR $(75$ $\left.\mathrm{MHz} \mathrm{CDCl}_{3}\right) \delta / \mathrm{ppm}=136.9,136.6,132.6,97.5,65.7,25.6$. HRMS (EI) calculated for $\mathrm{C}_{15} \mathrm{H}_{25} \mathrm{IO}_{3} \mathrm{Si}[\mathrm{M}]^{+}$408.0618, found 408.0613 .

Synthesis of 4-(Triisopropoxysilyl)-azidobenzene (1). Cul (210 mg, $1.10 \mathrm{mmol})$ was put into a $50 \mathrm{~mL}$ Schlenk-flask and dissolved in DMSO (15 mL). NaL-prolinate (304 mg, 2.22 mmol), $\mathrm{NaN}_{3}$ (970 mg, $\left.14.9 \mathrm{mmol}\right)$ and $3(3.06 \mathrm{~g}, 7.48 \mathrm{mmol})$ were added to the solution., The mixture was heated to $65^{\circ} \mathrm{C}$, stirred and monitored by TLC and ${ }^{1} \mathrm{H}$ NMR. After $6.5 \mathrm{~h}$, $\mathrm{NaN}_{3}$ (310 mg, $4.77 \mathrm{mmol}$ ) was added. The reaction was stirred for $1 \mathrm{~h}$. Then, the solution was poured into a separation funnel and $\mathrm{Et}_{2} \mathrm{O}$ $(100 \mathrm{~mL})$ and $\mathrm{H}_{2} \mathrm{O}(100 \mathrm{~mL})$ were added. The phases were separated and the aqueous phase was extracted with $\mathrm{Et}_{2} \mathrm{O}(75 \mathrm{~mL} \times 3)$. The combined organic phases were washed with brine $(100 \mathrm{~mL})$, dried over $\mathrm{MgSO}_{4}$ and the solvent was removed under reduced pressure. The product was purified by column chromatography with gradient elution (cyclohexane: $\mathrm{CH}_{2} \mathrm{Cl}_{2}=9: 1(2 \mathrm{~L})$, cyclohexane : $\mathrm{CH}_{2} \mathrm{Cl}_{2}=4: 1$ (1 L) cyclohexane : $\mathrm{CH}_{2} \mathrm{Cl}_{2}=1: 1(1 \mathrm{~L})$, with $1 \% \mathrm{Et}_{3} \mathrm{~N}$ in each eluent). 4(Triisopropoxysilyl)-azidobenzene (1) was obtained as yellow oil (826 mg, $34 \%) .{ }^{1} \mathrm{H}$ NMR $\left(300 \mathrm{MHz}, \mathrm{CDCl}_{3}\right) \delta / \mathrm{ppm}=7.66(\mathrm{~m}, 2 \mathrm{H}), 7.02$ $(\mathrm{m}, 2 \mathrm{H}), 4.25$ (septet, $\mathrm{J}=6.1 \mathrm{~Hz}, 3 \mathrm{H}), 1.21(\mathrm{~d}, \mathrm{~J}=6.1 \mathrm{~Hz}, 18 \mathrm{H}) \cdot{ }^{13} \mathrm{C}$ NMR $\left(75 \mathrm{MHz}_{1} \mathrm{CDCl}_{3}\right) \delta / \mathrm{ppm}=141.8,136.6,129.7,118.5,65.6,25.6$. HRMS (EI) calculated for $\mathrm{C}_{15} \mathrm{H}_{25} \mathrm{~N}_{3} \mathrm{O}_{3} \mathrm{Si}[\mathrm{M}]^{+}$323.1665, found 323.1660. IR (ATR) $\tilde{v} / \mathrm{cm}^{-1}=2971(\mathrm{~m}), 2126(\mathrm{~m}), 2094(\mathrm{~m}), 1592(\mathrm{w}), 1381(\mathrm{~m}), 1369$ $(\mathrm{m}), 1290(\mathrm{~m}), 1173(\mathrm{~m}), 1112(\mathrm{~s}), 1026(\mathrm{~s}), 887(\mathrm{~m}), 870(\mathrm{~m}), 817(\mathrm{~m})$, $756(\mathrm{~m}), 719(\mathrm{~m}) \mathrm{cm}^{-1}$.

General procedure for Phenylazide materials (MatPhN ${ }_{3}$ 1/34). A $250 \mathrm{~mL}$ polyethylene flask was filled with Pluronic ${ }^{\circledR} \mathrm{P} 123$ (SDA) $(2.64 \mathrm{~g}$, $0.45 \mathrm{mmol})$ and aqueous $\mathrm{HCl}(106 \mathrm{~mL}, \mathrm{pH} 1.5)$ was added. A mixture of $\mathrm{Si}(\mathrm{OEt})_{4}(5.49 \mathrm{~g}, 26.3 \mathrm{mmol})$ and $1(251 \mathrm{mg}, 0.77 \mathrm{mmol})$ was added. The resulting solution was stirred for $2 \mathrm{~h}$ at $25^{\circ} \mathrm{C}$. The solution was heated to $40^{\circ} \mathrm{C}$ and $\mathrm{NaF}$ (50.3 mg, $1.20 \mathrm{mmol}$ ) was added under stirring (400 rpm). The turbid mixture was stirred for $72 \mathrm{~h}$ at $40^{\circ} \mathrm{C}$. The solid was filtered off and washed with $\mathrm{H}_{2} \mathrm{O}(125 \mathrm{~mL} \times 3)$. The resulting yellowish solid was suspended in a mixture of pyridine $(17.5 \mathrm{~mL}), \mathrm{H}_{2} \mathrm{O}(17.5 \mathrm{~mL})$ and aqueous $\mathrm{HCl}(5.8 \mathrm{~mL}, 2 \mathrm{M})$. The slurry was stirred for $12 \mathrm{~h}$ at $70^{\circ} \mathrm{C}$. The solid was filtered off, washed with $\mathrm{H}_{2} \mathrm{O}(125 \mathrm{~mL} \times 3)$, acetone $(125 \mathrm{~mL} \times 3)$, and $\mathrm{Et}_{2} \mathrm{O}(125 \mathrm{~mL} \times 3)$ and dried under high vacuum (10${ }^{5} \mathrm{mbar}, 25^{\circ} \mathrm{C}, 16 \mathrm{~h}$ ) Note the increased thermal sensitivity of this material compared to the previously reported 3-n-propylazide system. MatPhN 1/34 was obtained as a pale yellow powder $(1.54 \mathrm{~g}) .{ }^{1} \mathrm{H}$ MAS-SSNMR $(700 \mathrm{MHz}) \delta / \mathrm{ppm}=8.20(\mathrm{~s}), 7.44(\mathrm{~s}), 2.37$ (broad, as.).$^{13} \mathrm{C}$ MASSSNMR $(100 \mathrm{MHz}) \delta / \mathrm{ppm}=143.9$, 135.2, 127.0, 117.4. ${ }^{29} \mathrm{Si}$ MASSSNMR $(139 \mathrm{MHz}) \delta / \mathrm{ppm}=-90.1,-101.1,-110.5$. IR $(\mathrm{DRIFT}) \tilde{v} / \mathrm{cm}^{-1}=$ 3740, 3547, 2134, 2104, 1598, 1503. Surface area (BET, N $2,77 \mathrm{~K}) 982$ $\mathrm{m}^{2} / \mathrm{g}$, pore diameter $\left(\mathrm{BJH} \mathrm{N} \mathrm{N}_{2}, 77 \mathrm{~K}\right) 9.3 \mathrm{~nm}$.

General procedure for Aniline materials (MatPhNH ${ }_{2}$ 1/34). MatPhN $1 / 34(1.04 \mathrm{~g})$ was suspended in THF $(35 \mathrm{~mL})$ and cooled to $0{ }^{\circ} \mathrm{C}$ Dimethylphenylphosphine $(0.65 \mathrm{~mL}, 4.53 \mathrm{mmol})$ was added. After complete addition, the yellow suspension was warmed to $25^{\circ} \mathrm{C}$ and stirred for $18 \mathrm{~h}$. $\mathrm{MeOH}(30 \mathrm{~mL})$ was added, and after $40 \mathrm{~min} \mathrm{H}_{2} \mathrm{O}(20 \mathrm{~mL})$ was added. After 20 min the solid was filtered off and washed with $\mathrm{H}_{2} \mathrm{O}$ $(125 \mathrm{~mL} \times 3)$ and $\mathrm{MeOH}(125 \mathrm{~mL} \times 3)$. The material was washed by Soxleth extraction $(\mathrm{MeOH})$ for $48 \mathrm{~h}$. Then, the solid was filtered off, washed with $\mathrm{MeOH}(125 \mathrm{~mL} \times 3)$, acetone $(125 \mathrm{~mL} \times 3)$, and $\mathrm{Et}_{2} \mathrm{O}(125$ $\mathrm{mL} \times 3)$, and dried under high vacuum $\left(10^{-5} \mathrm{mbar}, 140^{\circ} \mathrm{C}, 5 \mathrm{~h}\right)$. MatPhNH 2 1/34 (6), was obtained as white powder $(850 \mathrm{mg}) .{ }^{13} \mathrm{C}$ MAS- 
SSNMR $(176 \mathrm{MHz}) \delta / \mathrm{ppm}=149.0135 .5,113.2,49.0 .{ }^{29} \mathrm{Si}$ MAS-SSNMR $(139 \mathrm{MHz}) \delta / \mathrm{ppm}=-94.5,-102.4,-110.7 . \mathrm{IR}(\mathrm{DRIFT}) \tilde{v} / \mathrm{cm}^{-1}=3731$, $3470,2955,2853,1625,1603,1512,1464$. Surface area $\left(B E T, N_{2}, 77 \mathrm{~K}\right)$ $848 \mathrm{~m}^{2} / \mathrm{g}$; pore diameter $\left(\mathrm{BJH} \mathrm{N}_{2}, 77 \mathrm{~K}\right) 8.1 \mathrm{~nm}$.

\section{General procedure for HYPSO-4 (MatPhTEMPO 1/34). MatPhNH $\mathbf{~}_{2} \mathbf{3 4}$} (327 mg) was put into a $50 \mathrm{~mL}$ Schlenk-flask and suspended in $\mathrm{CH}_{2} \mathrm{Cl}_{2}(9$ $\mathrm{mL}$ ). A mixture of 4-(dimethylamino)-pyridine (DMAP) $(10.3 \mathrm{mg}$ $0.08 \mathrm{mmol})$ and $5(288 \mathrm{mg}, 0.75 \mathrm{mmol})$ was added and the resulting orange suspension was stirred for $48 \mathrm{~h}$ at room temperature. The solid was filtered off, washed with $\mathrm{CH}_{2} \mathrm{Cl}_{2}(75 \mathrm{~mL} \times 3)$, THF $(75 \mathrm{~mL} \times 3), \mathrm{H}_{2} \mathrm{O}$ $(75 \mathrm{~mL} \times 3)$, acetone $(75 \mathrm{~mL} \times 3)$ and $\mathrm{Et}_{2} \mathrm{O}(75 \mathrm{~mL} \times 3)$. The resulting pale orange solid was transferred into a $20 \mathrm{~mL}$ Schlenk-flask and $\mathrm{H}_{2} \mathrm{O}$ $(7 \mathrm{~mL})$ was added. The suspension was stirred at $50^{\circ} \mathrm{C}$ for $20 \mathrm{~h}$. The solid was filtered off, washed with acetone $(10 \mathrm{~mL} \times 3)$ and $\mathrm{Et}_{2} \mathrm{O}(10$ $\mathrm{mL} \times 3)$ and dried under high vacuum $\left(10^{-5} \mathrm{mbar}, 140^{\circ} \mathrm{C}, 12 \mathrm{~h}\right)$. HYPSO4 1/34 was obtained as pale orange powder $(200 \mathrm{mg})$. IR (DRIFT) $\tilde{v} / \mathrm{cm}^{-1}$ $=3735,3522,2958,2922,1625,1603,1512,1462$. Surface area (BET, $\left.\mathrm{N}_{2}, 77 \mathrm{~K}\right) 841 \mathrm{~m}^{2} / \mathrm{g}$; pore diameter $\left(\mathrm{BJH} \mathrm{N}_{2}, 77 \mathrm{~K}\right) 8.1 \mathrm{~nm}$. Radical concentration (CW EPR): $0.16 \mathrm{mmol} / \mathrm{g}$.

\section{Acknowledgment}

We acknowledge financial support from the Swiss National Science Foundation, the ETH Zürich, EPFL, and Bruker BioSpin AG. We also want to thank Prof. L. Emsley (EPFL) for helpful discussions.

\section{Abbreviations}

DMAP, 4-dimethylaminopyridine; DNP, dynamic nuclear polarization; DDNP, dissolution DNP; EO, ethyleneoxide; Mat, material; MAS, magic-angle spinning; Ph, Phenyl; PO, propyleneoxide; Pr, 1,3-n-propylene; TEMPO, 2,2,6,6tetramethylpiperidin-1-oxyl.

KEYWORDS Hybrid Materials, Sol-Gel, Hyperpolarization, Dynamic Nuclear Polarization.

\section{References}

[1] a) R. A. Green, R. W. Adams, S. B. Duckett, R. E. Mewis, D. C. Williamson, G. G. R. Green, Prog. Nucl. Magn. Reson. Spectrosc. 2012, $67,1-48$; b) C. Griesinger, M. Bennati, H. M. Vieth, C. Luchinat, G. Parigi, P. Höfer, F. Engelke, S. J. Glaser, V. Denysenkov, T. F. Prisner, Prog. Nucl. Magn. Reson. Spectrosc. 2012, 64, 4-28; c) G. Jeschke, L. Frydman, J. Magn. Reson. 2016, 264, 1-2

[2] a) A. J. Rossini, A. Zagdoun, M. Lelli, A. Lesage, C. Coperet, L. Emsley, Acc. Chem. Res. 2013, 46, 1942-1951; b) Q. Z. Ni, E. Daviso, T. V. Can, E. Markhasin, S. K. Jawla, T. M. Swager, R. J. Temkin, J. Herzfeld, R. G. Griffin, Acc. Chem. Res. 2013, 46, 1933-1941. c) J. H. AddenkjaerLarsen J. Magn. Res. 2016, 264, 3.

[3] a) A. W. Overhauser, Physical Review 1953, 91, 476-476; b) T. R. Carver, C. P. Slichter, Physical Review 1953, 92, 212-213.

[4] a) C. T. Farrar, D. A. Hall, G. J. Gerfen, S. J. Inati, R. G. Griffin, J. Chem. Phys. 2001, 114, 4922; b) W. T. Wenckebach, Appl. Magn. Reson. 2008
227-235; c) K. N. Hu, Solid State Nucl. Magn. Reson. 2011, 40, 31-41; d) K. N. Hu, G. T. Debelouchina, A. A. Smith, R. G. Griffin, J. Chem. Phys 2011, 134, 125105; e) Y. Hovav, A. Feintuch, S. Vega, J. Chem. Phys 2011, 134, 074509; f) Y. Hovav, A. Feintuch, S. Vega, J. Magn. Reson. 2012, 214, 29-41; g) S. S. Colombo, M. Filibian, P. Carretta, A. Rosso, F. Tedoldi, PCCP 2014, 16, 753-764.

[5] U. L. Gunther, Top. Curr. Chem. 2011.

[6] a) K.-N. Hu, H.-H. Yu, T. M. Swager, R. G. Griffin, J. Am. Chem. Soc. 2004, 126, 10844-10845; b) Y. Matsuki, T. Maly, O. Ouari, H. Karoui, F. Le Moigne, E. Rizzato, S. Lyubenova, J. Herzfeld, T. Prisner, P. Tordo, R G. Griffin, Angew. Chem. Int. Ed. 2009, 48, 4996-5000, S4996/4991S4996/4998; c) C. Ysacco, H. Karoui, G. Casano, F. Le Moigne, S. Combes, A. Rockenbauer, M. Rosay, W. Maas, O. Ouari, P. Tordo, Appl. Magn. Reson. 2012, 43, 251-261.

[7] a) D. Gajan, M. Schwarzwälder, M. P. Conley, W. R. Grüning, A. J. Rossini, A. Zagdoun, M. Lelli, M. Yulikov, G. Jeschke, C. Sauvée, O. Ouari, P. Tordo, L. Veyre, A. Lesage, C. Thieuleux, L. Emsley, C. Copéret, J. Am. Chem. Soc. 2013, 135, 15459-15466; b) D. Gajan, A. Bornet, B. Vuichoud, J. Milani, R. Melzi, H. A. van Kalkeren, L. Veyre, C. Thieuleux, M. P. Conley, W. R. Gruning, M. Schwarzwalder, A. Lesage, C. Coperet, G. Bodenhausen, L. Emsley, S. Jannin, Proc. Natl. Acad. Sci. U. S. A 2014, 111, 14693-14697

[8] a) M. K. Samantaray, J. Alauzun, D. Gajan, S. Kavitake, A. Mehdi, L. Veyre, M. Lelli, A. Lesage, L. Emsley, C. Copéret, C. Thieuleux, J. Am Chem. Soc. 2013, 135, 3193-3199; b) M. P. Conley, C. Copéret, C. Thieuleux, ACS Catalysis 2014, 4, 1458-1469; c) I. Romanenko, D. Gajan, R. Sayah, D. Crozet, E. Jeanneau, C. Lucas, L. Leroux, L. Veyre, A Lesage, L. Emsley, E. Lacôte, C. Thieuleux, Angew. Chem. Int. Ed. 2015 54, 12937-12941.

[9] F. Lerouge, G. Cerveau, R. J. P. Corriu, J. Mater. Chem. 2006, 16, 90-95. [10] W. Zhu, D. Ma, Chem. Commun. 2004, 888-889.

[11] a) J. Nakazawa, T. D. P. Stack, J. Am. Chem. Soc. 2008, 130, 14360 14361 ; b) A. Roussey, D. Gajan, T. K. Maishal, A. Mukerjee, L. Veyre, A Lesage, L. Emsley, C. Coperet, C. Thieuleux, PCCP 2011, 13, 4230 4233; c) J. Nakazawa, B. J. Smith, T. D. P. Stack, J. Am. Chem. Soc 2012, 134, 2750-2759; d) A. Zagdoun, G. Casano, O. Ouari, G. Lapadula A. J. Rossini, M. Lelli, M. Baffert, D. Gajan, L. Veyre, W. E. Maas, M. Rosay, R. T. Weber, C. Thieuleux, C. Coperet, A. Lesage, P. Tordo, L. Emsley, J. Am. Chem. Soc. 2012, 134, 2284-2291.

[12] D. Gajan, C. Coperet, New J. Chem. 2011, 35, 2403-2408.

[13] S. Brunauer, P. H. Emmett, E. Teller, J. Am. Chem. Soc. 1938, 60, 309319.

[14] E. P. Barrett, L. G. Joyner, P. P. Halenda, J. Am. Chem. Soc. 1951, 73, 373-380.

[15] H. Staudinger, J. Meyer, Helv. Chim. Acta 1919, 2, 635-646.

[16] a) L. K. Dyall, J. E. Kemp, Aust. J. Chem. 1967, 20, 1395-1402; b) M. W. Nydegger, S. Dutta, C. M. Cheatum, J. Chem. Phys. 2010, 133, 134506.

[17]a) M. Lelli, D. Gajan, A. Lesage, M. A. Caporini, V. Vitzthum, P. Mieville, F. Heroguel, F. Rascon, A. Roussey, C. Thieuleux, M. Boualleg, L. Veyre, G. Bodenhausen, C. Coperet, L. Emsley, J. Am. Chem. Soc. 2011, 133 , 2104-2107; b) A. J. Rossini, A. Zagdoun, M. Lelli, A. Lesage, C. Copéret, L. Emsley, Acc. Chem. Res. 2013, 46, 1942-1951.

[18] S. Jannin, A. Bornet, R. Melzi, G. Bodenhausen, Chem. Phys. Lett. 2012, 549, 99-102 
Synthesis of a tailored hyper polarizing solid matrix towards more efficient solidstate and dissolution DNP.

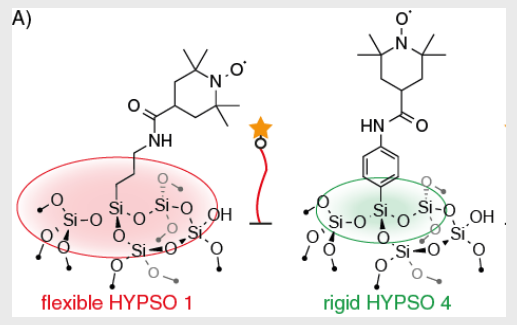

Author(s), Corresponding Author(s)*

Page No. - Page No.

Title 
